\title{
Effects of fatty acid activation on photosynthetic production of fatty acid-based biofuels in Synechocystis sp. PCC6803
}

\author{
Qianqian Gao ${ }^{1,2}$, Weihua Wang ${ }^{1}$, Hui Zhao ${ }^{1}$ and Xuefeng Lu ${ }^{1 *}$
}

\begin{abstract}
Background: Direct conversion of solar energy and carbon dioxide to drop in fuel molecules in a single biological system can be achieved from fatty acid-based biofuels such as fatty alcohols and alkanes. These molecules have similar properties to fossil fuels but can be produced by photosynthetic cyanobacteria.

Results: Synechocystis sp. PCC6803 mutant strains containing either overexpression or deletion of the s/r1609 gene, which encodes an acyl-ACP synthetase (AAS), have been constructed. The complete segregation and deletion in all mutant strains was confirmed by PCR analysis. Blocking fatty acid activation by deleting s/r1609 gene in wild-type Synechocystis sp. PCC6803 led to a doubling of the amount of free fatty acids and a decrease of alkane production by up to 90 percent. Overexpression of s/r1609 gene in the wild-type Synechocystis sp. PCC6803 had no effect on the production of either free fatty acids or alkanes. Overexpression or deletion of s/r1609 gene in the Synechocystis sp. PCC6803 mutant strain with the capability of making fatty alcohols by genetically introducing fatty acyl-CoA reductase respectively enhanced or reduced fatty alcohol production by 60 percent.
\end{abstract}

Conclusions: Fatty acid activation functionalized by the s/r1609 gene is metabolically crucial for biosynthesis of fatty acid derivatives in Synechocystis sp. PCC6803. It is necessary but not sufficient for efficient production of alkanes. Fatty alcohol production can be significantly improved by the overexpression of s/r1609 gene.

Keywords: Biofuel, Fatty alcohol, Fatty alkane, Cyanobacteria, Synechocystis sp. PCC6803, Fatty acid activation

\section{Background}

Biofuel production from renewable sources is considered as a feasible solution to the energy and environmental problems we are facing. It is very important to explore and develop advanced biofuels alongside traditional biofuels such as bioethanol and biodiesel to ensure sufficient supply of renewable energy at a time when demand for energy is set to increase over the coming decades. Advanced biofuels possess higher energy density, hydrophobic properties and compatibility with existing liquid fuel infrastructure including fuel engines, refinery equipment and transportation/distribution pipelines, whilst serving as better alternatives to fuels produced from fossil fuels [1].

\footnotetext{
* Correspondence: Ivxf@qibebt.ac.cn

${ }^{1}$ Key Laboratory of Biofuels, Qingdao Institute of Bioenergy and Bioprocess Technology, Chinese Academy of Sciences, No. 189 Songling Road, Qingdao 266101, China

Full list of author information is available at the end of the article
}

In terms of fuel properties the best replacement of petroleum fuels is "Petroleum Fuels". This means ideal biofuels produced from biological systems should be chemically similar to petroleum, such as fatty acid-based molecules including fatty alcohols and fatty alkanes [2].

As a candidate for biofuel-producing microbial systems, cyanobacteria have become more and more attractive due to their specific characteristics as photosynthetic bacteria.

Compared to generally utilized biofuel-producing microbes such as E. coli and S.cerevisiae, cyanobacteria are photosynthetic microbes, which can convert solar energy and carbon dioxide more efficiently into biofuels in one biological system. In contrast to plants and eukaryotic algae, cyanobacteria are prokaryotic microbes with the ability to grow a lot faster. Genetic engineering platforms for cyanobacteria are well established and they are highly tolerable to heterogeneous genes. So far over 40 genomic sequences of cyanobacteria strains are available, therefore
C Biomed Central

C 2012 Gao et al; licensee BioMed Central Ltd. This is an Open Access article distributed under the terms of the Creative Commons Attribution License (http://creativecommons.org/licenses/by/2.0), which permits unrestricted use, distribution, and reproduction in any medium, provided the original work is properly cited. 
genetic information on cyanobacteria are relatively robust http://genome.kazusa.or.jp/cyanobase. This makes genetic engineering toward efficiently producing biofuels in cyanobacteria to be a more realistic and feasible option [3-5].

Recently, the alkane biosynthetic pathway was identified in cyanobacteria with two enzyme families including an acyl carrier protein (ACP) reductase (AAR) and an aldehyde decarbonylase (ADC) [6]. Genes associated with an alcohol-forming fatty acyl-CoA reductase (FAR) have not been reported in cyanobacteria, C16:0 and C18:0 alcohols can be produced by engineered cyanobacteria containing the FAR gene derived from jojoba [7] or Arabidopsis thaliana [4]. The overall pathway of the fatty acid, fatty alcohol and fatty alkane in wild-type or engineered Synechocystis strains were illustrated in Figure 1.

The fatty acid molecules must be activated to fatty acyl-thioesters by fatty acyl-CoA synthetase (ACS, EC 6.2.1.3) or fatty acyl-ACP synthetase (AAS, EC 6.2.1.20) prior to the synthesis of fatty alcohols and alkanes. Based on sequence identity analysis, Synechocystis sp. PCC 6803 encodes only a single candidate gene for fatty acid activation, annotated as AAS and designated as slr1609 [8]. The slr1609-deletion cyanobacteria mutant was incapable of utilizing exogenous fatty acids and thus secreted endogenous fatty acids into the medium. The detected free fatty acids are released from membrane lipids. The data suggest a remarkable turnover of lipids and a role of AAS activity in recycling the released fatty acids [8].

The overall pathway of the fatty acid, fatty alcohol and alkane in wild-type or engineered Synechocystis strains are illustrated in Figure 1. Synechocystis sp. PCC6803 mutant strains with either overexpression or deletion of slr1609 gene have been constructed in this study. The results indicated that the AAS gene was metabolically crucial for production of free fatty acids and fatty acid derivatives in Synechocystis sp. PCC6803.

\section{Results and discussion}

Construction of Synechocystis sp. PCC6803 mutants with either overexpression or deletion of slr1609 gene

To investigate the impact of AAS on production of free fatty acids and fatty acid derivatives, we constructed two plasmids pGQ11 (Figure 2B) and pGQ49 (Figure 2D) for over-expressing slr1609 gene, driven by a strong constitutive promoter Prbc or PpsbA2 and integrated into slr0168 [9] or psbA2 site, respectively. Two plasmids pGQ53 (Figure 2A) and pGQ17 (Figure 2C) were constructed for disruption of slr1609 gene with erythromycin or kanamycin resistance cassettes, respectively. The plasmid pGQ11 or pGQ53 was transformed into Synechocystis sp. PCC6803 generating GQ3 and GQ8 strains respectively for analysis of fatty acid and alkane production. The plasmid pGQ49 or pGQ17 was transformed into fatty-alcohol-producing strain Syn-XT14 generating GQ5 and GQ6 respectively for analysis of fatty alcohol production. Overexpressed AAS protein with C-terminal His-tag in GQ3 and GQ5 mutant were detected by western blotting as shown in Additional file 1: Figure 1.

Due to cyanobacterial cells containing multiple copies of chromosomes [10], the complete replacement of wild type alleles must be established and confirmed by PCR (Figure 3 and 4). Primers used in this study were listed in Additional file 1: Table 1. Because the whole inserted fragment is too long to amplify from genomic DNA, the over-expressed genes were checked by two reactions for successful insertion and correct orientation of the slr1609 or FAR gene and complete replacement of wildtype alleles (Figure $3 \mathrm{~B}$ and 4 ). The first reaction with the primer (0168-2 or Pd1-3) of insert site and primer (1609NdeI, 1609R or far-1) for the inserted gene verified the genes were inserted in the correct orientation. The second reaction with primers $(0168-1 / 0168-2$ or $\mathrm{pD} 1-1 / \mathrm{p}$ $\mathrm{pD} 1-2 \mathrm{~d}-2)$ of inserted site verified the wild-type was

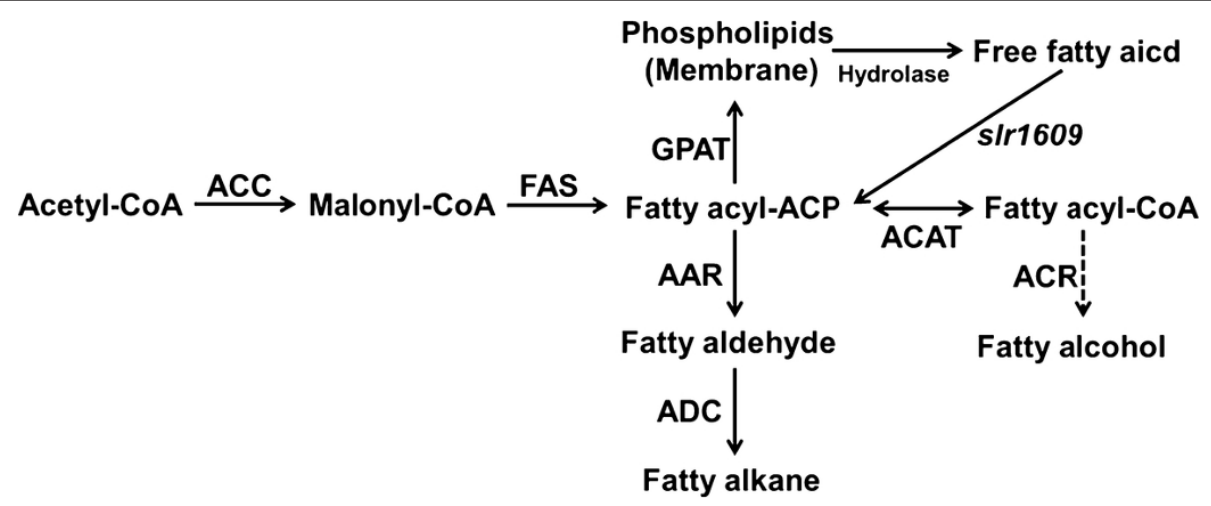

Figure 1 The overall pathway of the fatty acid, fatty alcohol and fatty alkane in Synechocystis sp. PCC 6803. Dash arrow represents nonnative and heterologously introduced pathway. ACP, acyl carrier protein; AAR, acyl-ACP reductase; ADC, aldehyde decarbonylase; ACC, acetylCoA carboxylase; FAS, fatty acid synthase; GPAT, glycerol-3-phosphate-acyl transferase; ACAT, acyl-CoA-ACP transferase; ACR, acyl-CoA reductase. 


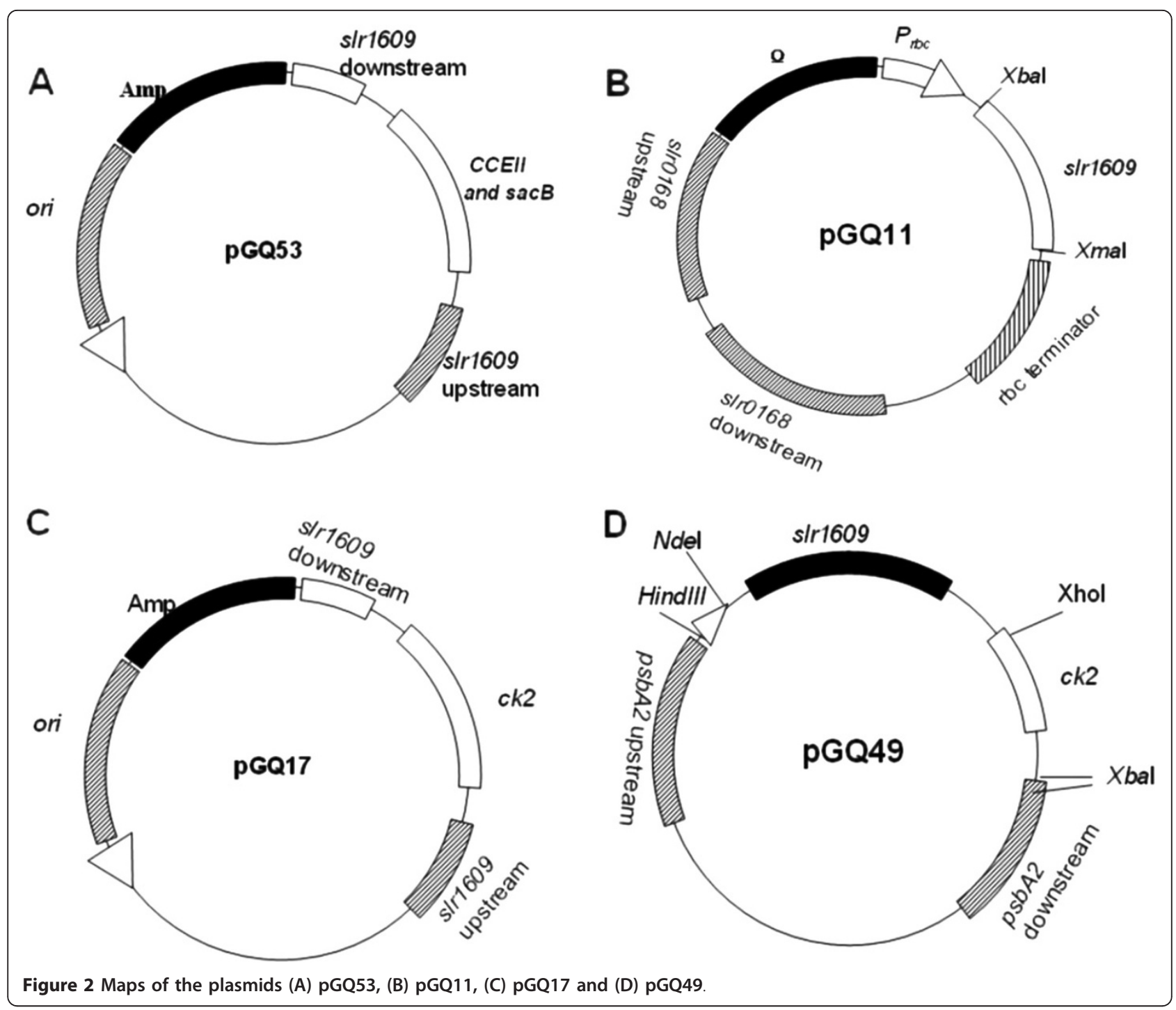

replaced completely (Figure $3 \mathrm{~B}$ and 4 ). The disrupted genes were checked with internal primers (Figure 3A and $4 \mathrm{~B})$ or primers that flanked the insertion site to prove the wild-type allele was replaced completely. The results of the PCR indicated the correct mutants were constructed.

The amount of free fatty acids can be doubled in the Synechocystis mutant strain with s/r1609 knockout

The total free fatty acids of the wild-type strain and the mutant strain GQ8 with slr1609 deletion were extracted using the methods described in the Experimental Procedures. The wild-type and the mutant strain displayed similar growth behaviors (Figure 5A). However, the content of free fatty acids showed substantial differences between two strains (Figure 5B). In the slr1609 deletion mutant, the concentration of total free fatty acids was 6.7 $\pm 0.2 \mu \mathrm{g} / \mathrm{mL} / \mathrm{OD}$, while that of the wild type was $3.5 \pm$ $0.25 \mu \mathrm{g} / \mathrm{mL} / \mathrm{OD}$. The deletion of slr1609 increased free fatty acid accumulation close to two folds. It indicates that the dysfunction of fatty acid activation caused by the deletion of slr1609 results in an increase of free fatty acid accumulation.

As to the contents of the pool of free fatty acids, the amount of unsaturated fatty acids with carbon chain length of $\mathrm{C} 16$ and $\mathrm{C} 18$ was significantly higher in the slr1609 knockout mutant strain compared to the wildtype strain. Double bonds can only be introduced into free fatty acid coupled to the glycerol backbone of membrane lipids by acyl-lipid-type desaturases. Indicating that unsaturated free fatty acids being released from membrane lipids of senescent or damaged cells, while unsaturated free fatty acids in AAS deletion mutant can not be recycled and incorporated to membrane lipids.

In the mutant strain GQ3 with slr1609 over-expression, there is no significant change to the production of free fatty acids compared to the wild-type strain (data not 


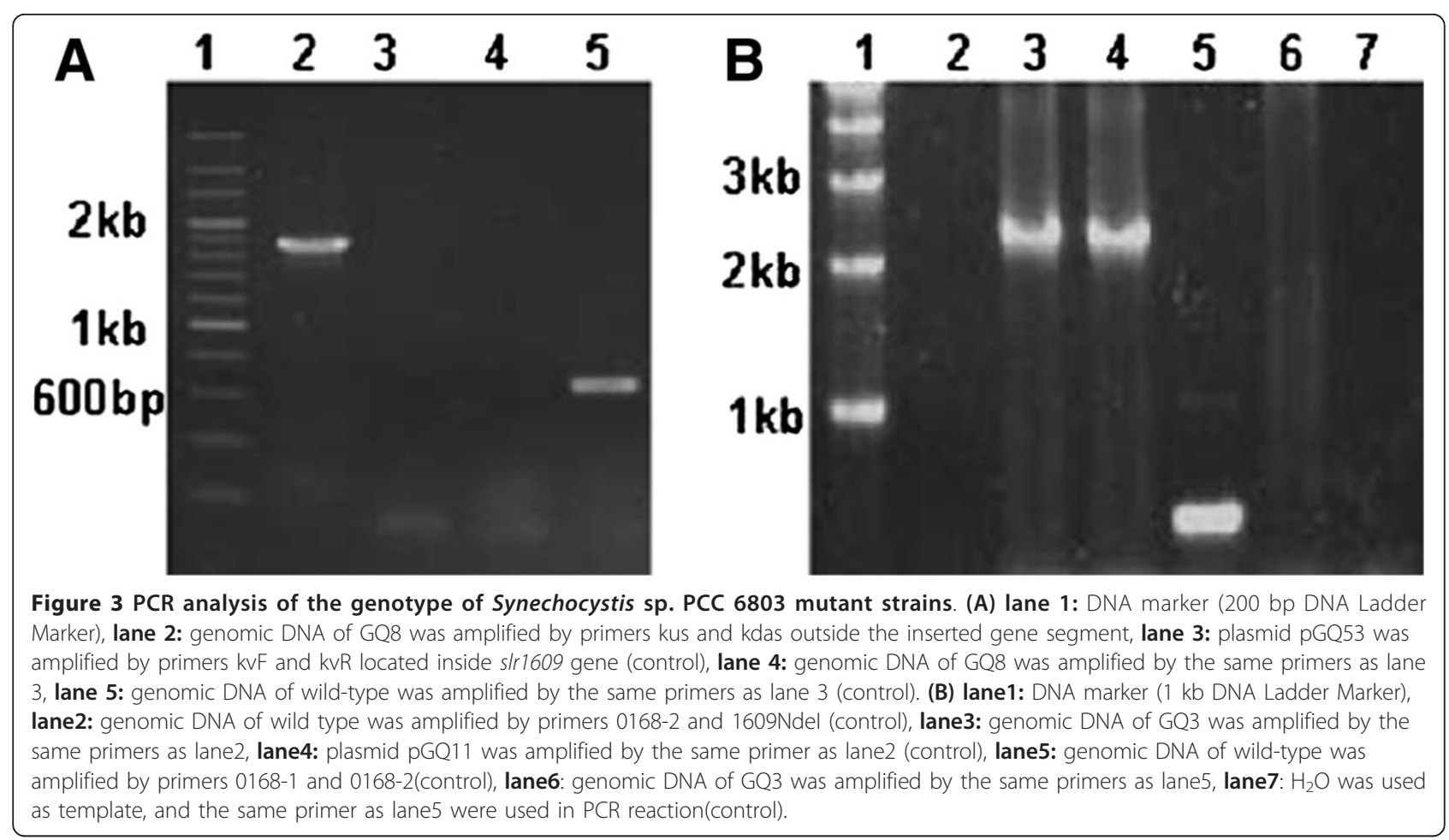

shown). It has been confirmed that free fatty acids are released from membrane lipids in Synechocystis sp. PCC6803 [10]. Indicating free fatty acid production is not only determined by the fatty acyl-ACP pool size, but also by the biosynthesis of membranes and hydrolysis of membrane lipids which are physiologically regulated.

\section{The production of alkanes was significantly reduced in the s/r1609 deletion mutant strain}

Alkanes are the predominant constituents of gasoline, diesel, and jet fuels. Production of alkanes has been reported in a diversity of cyanobacteria, with heptadecane and heptadecene being the most abundant hydrocarbons found in Synechocystis sp. PCC6803. In this pathway fatty acyl-ACP is reduced to a fatty aldehyde by a fatty acyl-ACP reductase (AAR) and then the fatty aldehyde decarbonylase (ADC) is able to convert the aldehyde into an alkane. Besides the fatty acyl-ACP produced by de novo fatty acid synthesis from acetyl-CoA, acyl-ACP synthetase (AAS) is essential for recycling fatty acids into fatty acyl-ACP. The results showed that the production of hydrocarbons was significantly reduced by around $90 \%$ in the mutant strain GQ8 with an slr1609 deletion $(0.047 \pm 0.01 \mu \mathrm{g} / \mathrm{mL} / \mathrm{OD})$ compared with the wild-type strain $(0.38 \pm 0.07 \mu \mathrm{g} / \mathrm{mL} / \mathrm{OD})$ (Figure $6 \mathrm{~B})$, and this indicates that AAS plays an essential role in alkane biosynthesis. AAS can enhance the total amount of fatty acyl-ACP available for alkane production, and the acyl-ACP formed by AAS activity may be more accessible to the acyl-ACP formed by de novo fatty acid synthesis.

The production of alkanes was not enhanced by the over-expressing slr1609 gene alone in the GQ3 strain $(0.39 \pm 0.03 \mu \mathrm{g} / \mathrm{mL} / \mathrm{OD})$ (Figure $6 \mathrm{~B})$. Due to the activities of downstream enzymes of the alkane producing pathway, AAR and ADC, are rather low and fatty acylACPs might not be efficiently converted to alkanes [11]. Fatty acyl-ACPs are also a supplier of fatty acyl groups for biosynthesis of lipid A [12], phospholipids [13], and membrane-derived lipo-polysaccharides [14].

\section{Synechocystis AAS plays an important role in fatty alcohol production}

Fatty alcohols possess carbon chain length which range from $\mathrm{C} 8$ to $\mathrm{C} 22$, and can be used as detergents, precursors for synthesis of other chemicals or fuels. We have constructed a fatty-alcohol-producing strain Syn-XT14, by the introduction of a jojoba acyl-CoA reductase gene into wide-type strain in previous work [4], and the effect of Synechocystis AAS on fatty alcohol production were examined by over-expressing (GQ5) or deleting the slr1609 gene (GQ6) in Syn-XT14. The results showed that fatty alcohol production was enhanced by about $60 \%$ in GQ5 $(19.8 \pm 2.3 \mu \mathrm{g} / \mathrm{L} / \mathrm{OD})$ or decreased by about $60 \%$ in GQ6 $(4.9 \pm 0.1 \mu \mathrm{g} / \mathrm{L} / \mathrm{OD})$ compared with Syn-XT14 $(12.5 \pm 2.0 \mu \mathrm{g} / \mathrm{L} / \mathrm{OD})$, respectively (Figure 7$)$. The data indicates that Synechocystis AAS plays an important role in fatty alcohol production. 

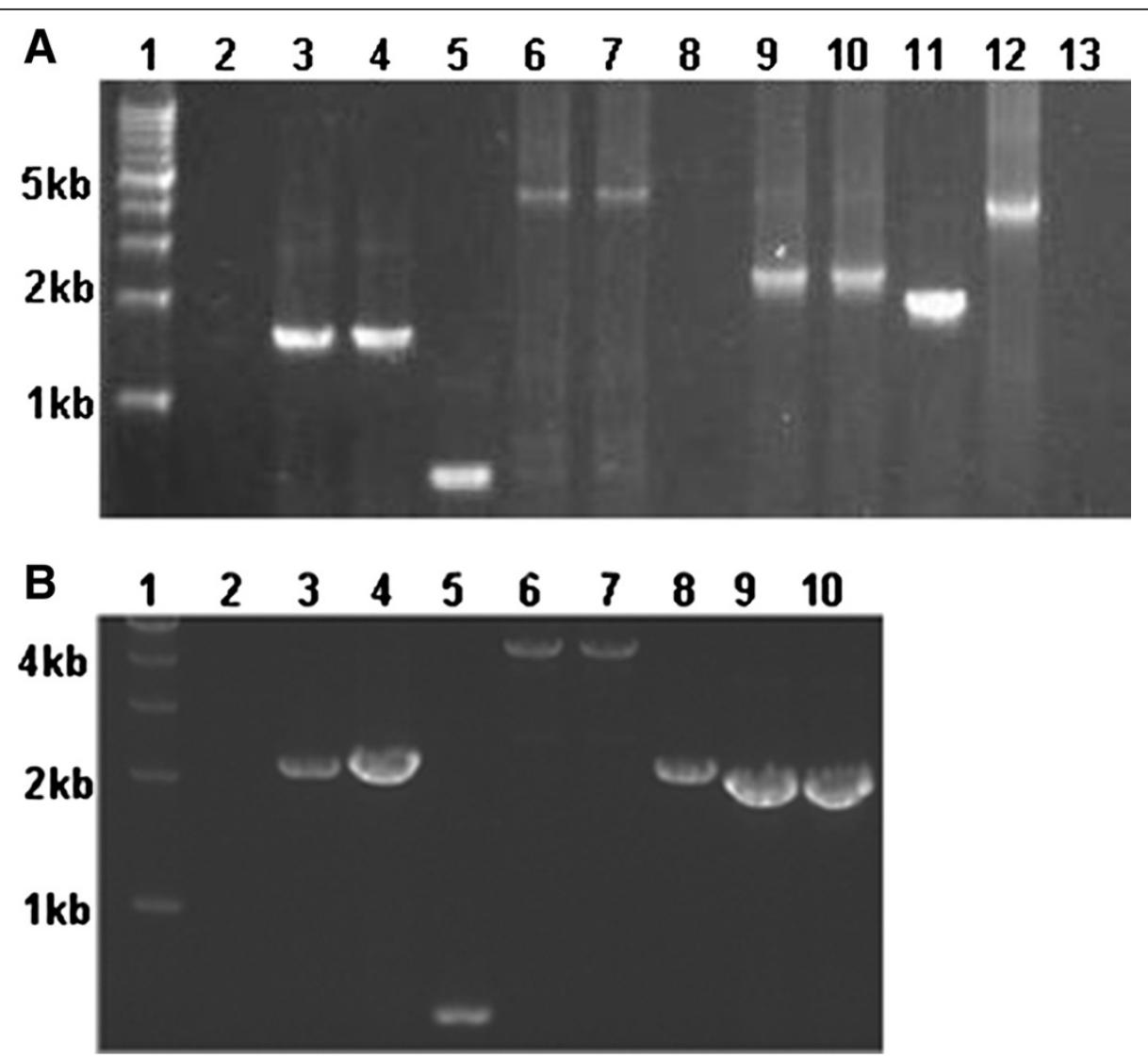

Figure 4 PCR analysis of the genotype of Synechocystis sp. PCC 6803 mutant strains. (A) lane1: DNA marker (1 kb DNA Ladder Marker) lane2: genomic DNA of wild-type was amplified by primers 0168-1 and far-1 (control), lane3: genomic DNA of GQ5 was amplified by the same primers as lane2, lane4: plasmid PXT14 was amplified by the same primers as lane2, lane5: genomic of wild-type was amplified by primers 0168-1 and 0168-2, lane6: genomic DNA of GQ5 was amplified by the same primers as lane5, lane7: plasmid pXT14 was amplified by the same primer as lane5 (control), lane8: genomic DNA of wild-type was amplified by primers pD1-3 and 1609R (control), lane9: genomic DNA of GQ5 was amplified by the same primers as lane8, lane10: plasmid pGQ49 was amplified by the same primers as lane8 (control), lane11: genomic DNA of wild-type was amplified by primers pD1-3 and pD1-2d-2 (control), lane12: genomic DNA of GQ5 was amplified by the same primers as lane11, lane13: plasmid pGQ49 was amplified by the same primers as lane11 (control). (B) lane1: DNA marker (1 kb DNA Ladder Marker), lane2: genomic DNA of wild-type was amplified by the primers 0168-1 and far-1 (control), lane3: genomic DNA of GQ6 was amplified by the same primers as lane2, lane4: plasmid pXT14 was amplified by the same primers as lane2 (control), lane5: genomic DNA of wild-type was amplified by primers 0168-1 and 0168-2 (control), lane6: genomic DNA of GQ6 was amplified by the same primers as lane5, lane7: plasmid pXT14 was amplified by the same primer as lane5 (control), lane8: genomic DNA of wild-type was amplified by primer 1609Ndel and 1609R (control, the size of target DNA fragment should be 2091 bp), lane9: genomic DNA of GQ6 was amplified by the same primers as lane8 (the size of target DNA fragment should be 1810 bp), lane10: plasmid pGQ17 was amplified by the same primers as lane8 (control, the size of target DNA fragment should be $1810 \mathrm{bp}$ ).

Although the native jojoba FAR has a preference for very-long-chain acyl-CoA substrate (C20, C22 and C24), assays of jojoba extracts indicated that it is capable of reducing $\mathrm{C} 16: 0-\mathrm{ACP}$ and $\mathrm{C} 18: 0-\mathrm{ACP}$ [7]. It's a reductase with broad substrate specificity. It may be possible that the acyl-ACP produced by AAS can also be accepted as substrate in addition to acyl-CoA by jojoba FAR in engineered Synechocystis strains. It is also possible that the acyl-ACPs, which are synthesized by Synechocystis AAS, could be in turn transacylated to acyl-CoAs by a reverse catalysis of acetyl-CoA-ACP-transacylase (EC 2.3.1.38) type reaction.

\section{Conclusions}

In this study the effects of fatty acid activation functionalized by a fatty acyl-ACP synthase on the production of fatty acid-based biofuels including fatty alcohols and alkanes in a photosynthetic cyanobacterium were evaluated and analyzed. We found fatty acid activation to be essential for efficient production of alkanes and plays a key role in manipulating fatty alcohol production. The results here provide promising clues for metabolically engineering cyanobacteria to improve photosynthetic production of fatty acidbased biofuels. 


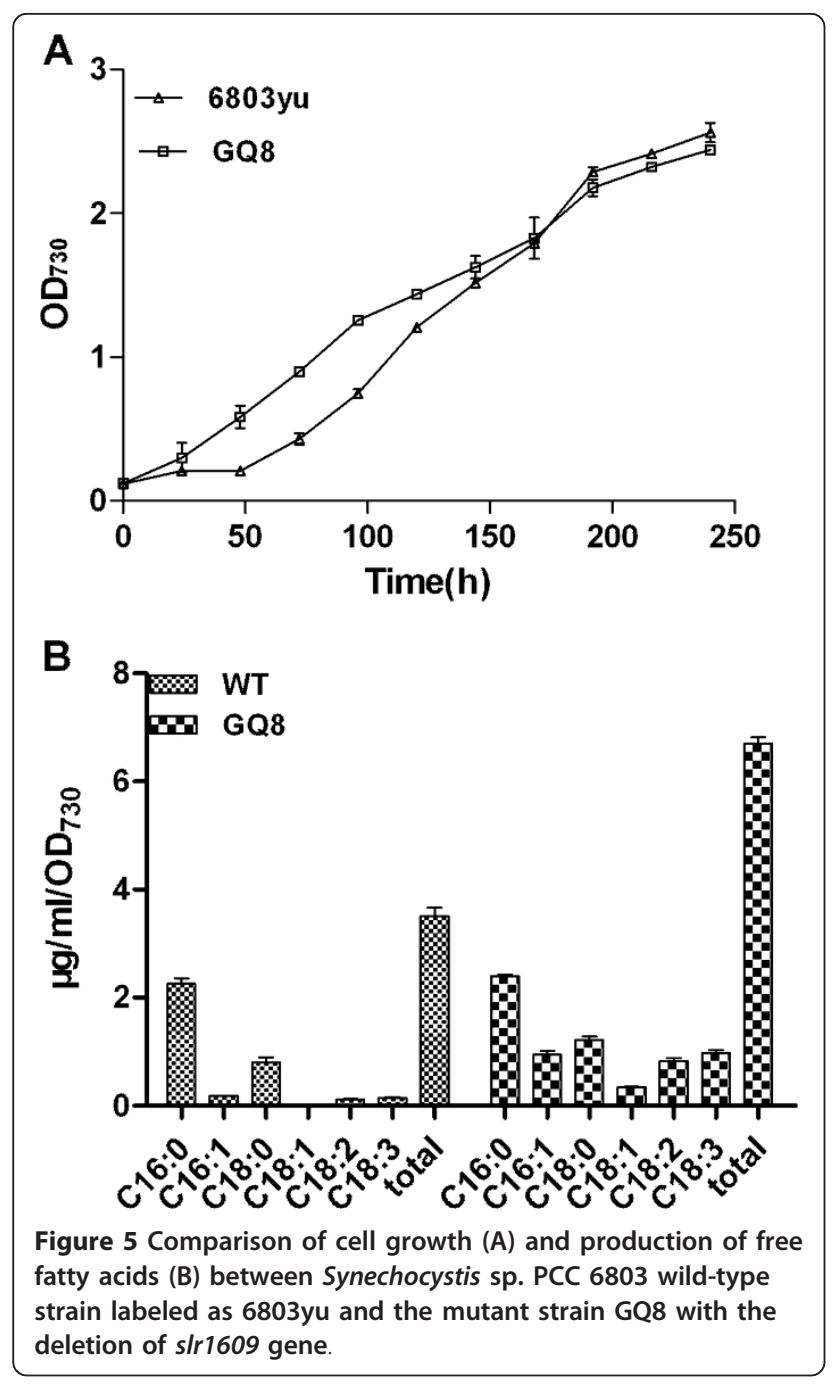

\section{Methods}

\section{Chemicals and reagents}

Pentadecanol, eicosane and nonadecanoic acid were obtained from Sigma-Aldrich (USA). Other chemicals were from Merck (Germany) or Ameresco (USA). Oligo nucleotides and gene synthesis were carried out by Sangon (Shanghai, China). Taq DNA polymerases and all restriction endonucleases were from Fermentas (Canada) or Takara (Japan). The DNA ladders were from Takara (Japan). The kits used for molecular cloning were from Omega (USA) or Takara (Japan).

\section{Construction of Synechocystis sp. PCC683 mutant strains}

All primers used in this study are listed in the Additional file 1 .

The slr1609 gene was amplified from the genomic DNA of Synechocystis sp. PCC6803 with the primers 1609NdeI/ 1609R and subcloned into NdeI/XhoI site of the plasmid pET21b (Novagen, USA) to generate the plasmid pGQ7.

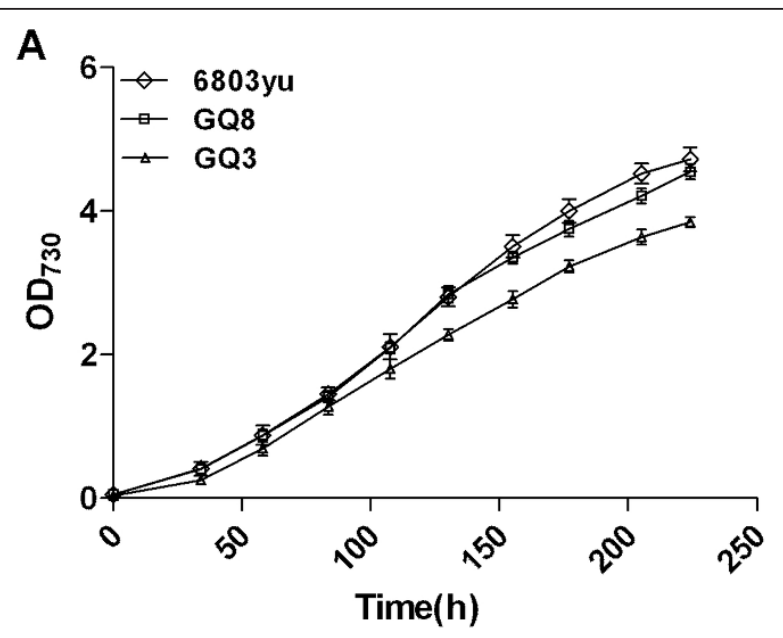

B

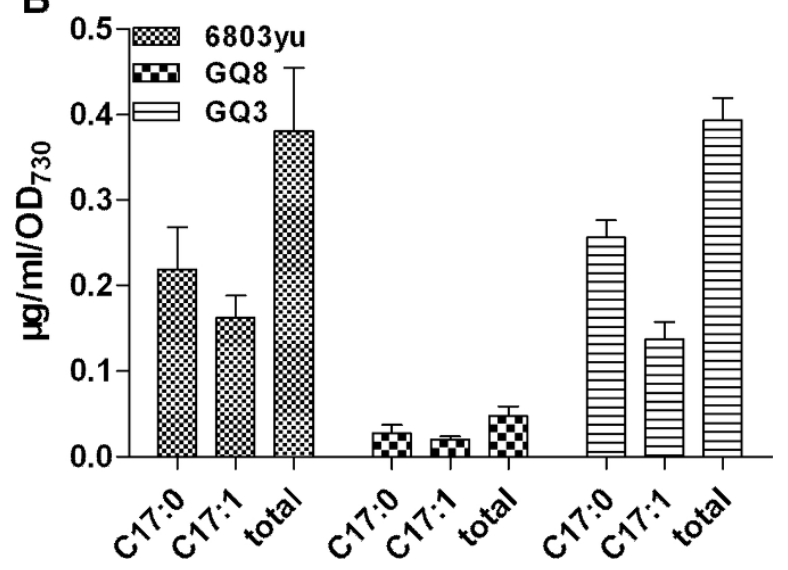

Figure 6 Comparison of cell growth (A) and production of fatty alkanes (B) in Synechocystis sp. PCC 6803 wild-type strain labeled as $6803 \mathrm{yu}$, the mutant strain GQ8 with the deletion of slr1609 gene and GQ3 with the overexpression of s/r1609 gene.

The gene was cloned from pGQ7 with the primers $1609 \mathrm{XbaI} / 1609 \mathrm{DraI}$ and subcloned into XbaI/SmaI site of the plasmid pFQ20 [4] to generate the plasmid pGQ11.

The plasmid pXT68 was constructed based on the site of psbA2 gene. Both upstream and downstream fragments of $p s b \mathrm{~A} 2$ gene were cloned from the genomic DNA of Synechocystis sp PCC6803 with the primers Pd1-2-f/Pd12-r and pD1-2 d-1/pD1-2 d-2 respectively and inserted into the TA cloning site of pMD18-T, to generate the plasmids pXT25 and pXT59. The kanamycin resistance $\left(\mathrm{kan}^{\mathrm{r}}\right)$ gene (ck2) cassette was excised with EcoRV and $\mathrm{Xba \textrm {I }}$ from pRL446 [15] and inserted into the Pst I site of pXT25 with blunt ends, to generate the plasmid pXT62. The $4.5 \mathrm{~kb}$ fragment containing $c k 2$ and upstream of $p s b \mathrm{~A} 2$ was excised with $\mathrm{Xba \textrm {I }}$ and $S p h \mathrm{I}$ from pXT62 and inserted into XbaI site of pXT59 with blunt ends, to generate the plasmid pXT68. Then, the slr1609 gene was excised with NdeI and DraIII (blunted end) from pGQ7 


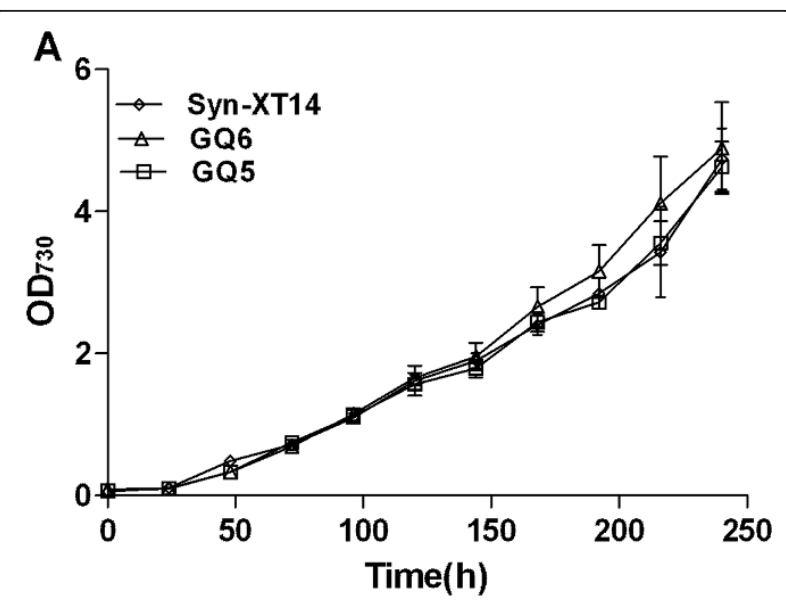

B

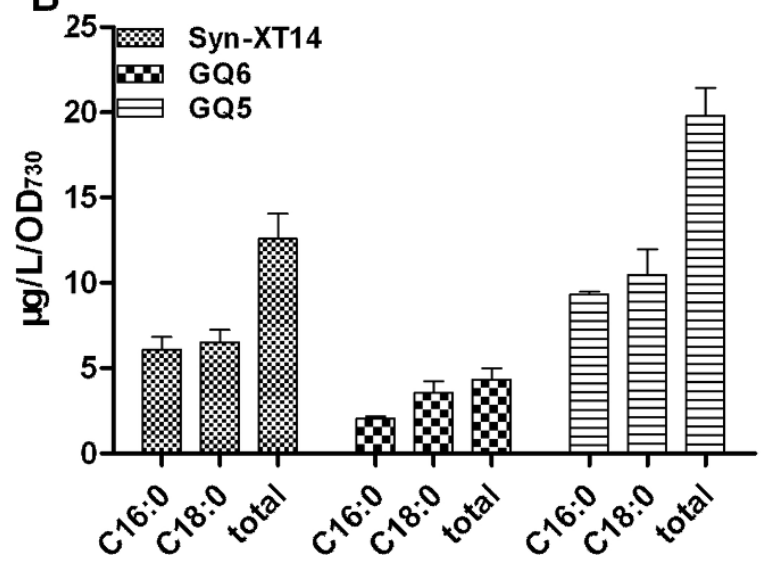

Figure 7 Comparison of cell growth (A) and production of fatty alcohols (B) in engineered fatty alcohol-producing strain SynXT14, GQ5 with the overexpression of s/r1609 gene and GQ6 with the deletion of s/r1609 gene.

and inserted into the NdeI/SalI (blunted end) site of pXT68, to generate the plasmid pGQ49.

The plasmids pGQ17 and pGQ53 were constructed and used to disrupt the slr1609 gene via homologous recombination in Synechocystis [16]. Genomic DNA was used as the template to amplify the $500 \mathrm{bp} \mathrm{N}$-terminal and C-terminal fragments of slr1609 ORF using the primers $1609 \mathrm{kuF} / \mathrm{R}$ and $1609 \mathrm{kdF} / \mathrm{R}$, respectively. The N-terminal and $\mathrm{C}$-terminal fragments were cloned into pMD18-T to generate the plasmids pGQ12 and pGQ13, respectively. The $c k 2$ gene from pRL446 [15] was cloned into the BamHI site of pGQ12 to generate plasmid pGQ14. After digestion with DraI and EcoRI and blunting by T4 DNA polymerase, the $c k 2$ gene together with $\mathrm{N}$-terminal fragment of slr1609 from pGQ14 were cloned into the SmaI site of plasmid pGQ13 to generate plasmid pGQ17. The erythromycin resistance gene cce 2 was digested with EcoRV from pRL271 [17] and cloned into the blunted BamHI site of pGQ17 to generate plasmid pGQ53.
Plasmids constructed and used in this study were listed in Table 1.

All of the constructs were checked by enzyme digestion and then transformed to Synechocystis sp. PCC6803 cells [18]. The plasmids pGQ11 and pGQ53 were transformed to Synechocystis sp. PCC6803 wild-type to generate the mutant strains GQ3 and GQ8 respectively. The plasmids pGQ17 and pGQ49 were transformed to Synechocystis sp. PCC6803 mutant strain Syn-XT14 [4] to generate two new mutant strains GQ6 and GQ5 respectively. For the initial selection of transformants, the DNA/cell mixture was applied to BG11 agar plates. After $18 \mathrm{~h}$ the membrane filters were applied to fresh BG11 agar plates containing antibiotics $\left(10 \mu \mathrm{g} \mathrm{mL}^{-1}\right.$ spectinomycin, $10 \mu \mathrm{g} \mathrm{mL} L^{-1}$ erythromycin or $5 \mu \mathrm{g} \mathrm{mL}^{-1} / 5$ $\mu \mathrm{g} \mathrm{mL} \mathrm{m}^{-1}$ spectinomycin/kanamycin). Homogeneous mutants were obtained by successive streaking on BG11 plates containing antibiotics. Complete segregation of all mutants was verified by employing PCR. Strains constructed and used in this study were listed in Table 2.

\section{Cultivation of Synechocystis sp. PCC683 strains}

Liquid cultures of Synechocystis sp. PCC 6803 were grown photo-autotrophically in BG 11 media [19] at $30^{\circ}$ $\mathrm{C}$ under constant illumination at a photosynthetic photon flux density of approximately $30 \mu \mathrm{mol}$ photons $\mathrm{m}^{-2} \mathrm{~s}^{-1}$ and with aeration by sterile air or in a shaker. When necessary, the following antibiotics were added: erythromycin $\left(20 \mu \mathrm{g} \mathrm{mL}^{-1}\right)$ and spectinomycin $(20 \mu \mathrm{g}$ $\mathrm{mL}^{-1}$ ). Growth was monitored by following the OD at $730 \mathrm{~nm}$. The Synechocystis sp. PCC6803 wild-type strain, the mutant strains GQ8 with deletion of the slr1609 gene and GQ3 with overexpression of the slr1609 gene were respectively grown in $100 \mathrm{~mL}$ Erlenmeyer flask containing $50 \mathrm{~mL}$ of BG11 medium in a shaker for free fatty acid analysis. The Synechocystis sp. PCC6803 wildtype strain, the mutant strains Syn-XT14 with overexpression of the FAR gene, GQ6 with deletion of the slr1609 gene and GQ5 with overexpression of the slr1609 gene were respectively grown in a $500 \mathrm{~mL}$ Erlenmeyer flask containing $300 \mathrm{~mL}$ of BG11 medium with aeration by sterile air for fatty alkane or fatty alcohol analysis. The Synechocystis sp. PCC6803 wild-type strain, the mutant strains GQ8 with deletion of the slr1609 gene and GQ3 with overexpression of the slr1609 gene were respectively grown in a $500 \mathrm{~mL}$ Erlenmeyer flask containing $300 \mathrm{~mL}$ of BG11 medium with aeration by sterile air for fatty alkane analysis.

\section{Extraction and analysis of free fatty acids, fatty alkanes and fatty alcohols}

For extraction of free fatty acids, $20 \mathrm{~mL}$ of the culture was lysed by sonication (total $30 \mathrm{~min}$ with $10 \mathrm{~s}$ on and $5 \mathrm{~s}$ off intervals) when the stationary phase (about 240 
Table 1 Plasmids constructed and used in this study

\begin{tabular}{|c|c|c|}
\hline Plasmid & Relevant characteristics ${ }^{a, b}$ & Reference \\
\hline pGQ7 & $A p^{r}, p E T 21 b$ derivative containing s/r1609gene, T7 promoter & This study \\
\hline pXT25 & $A p^{r}, p M D 18-T$ derivative containing upstream fragment of $p s b A 2, T 7$ promoter & This study \\
\hline pXT59 & $A p^{r}, p M D 18-T$ derivative containing downstream fragment of $p s b A 2, T 7$ promoter & This study \\
\hline pXT62 & $A p^{r}, K_{a n}^{r}$, pMD18-T derivative containing upstream fragment of psbA2 and CK2 & This study \\
\hline pXT68 & $A p^{r}, K_{a n}^{r}$, pMD18-T derivative containing upstream and downstream fragments of psbA2, CK2 and sacB & This study \\
\hline pFQ20 & $\mathrm{Ap}^{\mathrm{r}} \mathrm{Spe}^{\mathrm{r}}$, pKW1188SL derivative containing lacZ, $\mathrm{P}_{\mathrm{rbc}}$ promoter & [4] \\
\hline pGQ11 & $\mathrm{Ap}^{r} \mathrm{Spe}^{\mathrm{r}}, \mathrm{pFQ} 20$ derivative containing slr1609, $\mathrm{P}_{\mathrm{rbc}}$ promoter & This study \\
\hline pGQ49 & Kan', pXT68 derivative containing sIr1609, $\mathrm{P}_{\text {psba2 }}$ promoter & This study \\
\hline pGQ12 & $\mathrm{Ap}^{\mathrm{r}}, \mathrm{pMD18}$-T derivative containing upstream fragment of s/r1609, T7 promoter & This study \\
\hline pGQ13 & $\mathrm{Ap}^{\mathrm{r}}, \mathrm{pMD} 18-\mathrm{T}$ derivative containing downstream fragment of s/r1609, T7 promoter & This study \\
\hline pGQ14 & $\mathrm{Ap}^{r}, \mathrm{Kann}^{r}, \mathrm{pMD} 18-\mathrm{T}$ derivative containing upstream fragment of s/r1609 and CK2 & This study \\
\hline pGQ17 & $\mathrm{Ap}^{r}, \mathrm{Kan}^{r}$, pMD18-T derivative containing upstream and downstream fragments of s/r1609 and CK2 & This study \\
\hline pGQ53 & $\mathrm{Ap}^{r}, \mathrm{Cm}^{r}, \mathrm{Em}^{r}, \mathrm{pMD18}-\mathrm{T}$ derivative containing upstream and downstream fragments of s/r1609, CCEIl and sacB & This study \\
\hline pXT14 & Sper $^{r}$ pFQ20 derivative containing FAR gene (jojoba), $P_{r b c}$ promoter & [4] \\
\hline
\end{tabular}

${ }^{a}$ Ap, Ampicillin. Spe, Spectinomycin. Kan, kanamycin. Cm, Chloramphenicol. Em, Erythromycin.

${ }^{\mathrm{b}} \mathrm{CK} 2$ gene for kanamycin antibiotic resistance and CCEIl gene for erythromycin antibiotic resistance.

h) reached. To each $20 \mathrm{~mL}$ aliquot, $20 \mathrm{~mL}$ of $2: 1(\mathrm{v} / \mathrm{v})$ $\mathrm{CHCl}_{3}: \mathrm{CH}_{3} \mathrm{OH}$ were added and the resulting mixture was mixed well [20]. For GC-MS analysis of free fatty acids, $10 \mu \mathrm{g}$ of nonadecanoic acid was added as the internal standard. A two-phase system (top: aqueous, bottom: organic) was generated after shaking for $1 \mathrm{~h}$ and centrifugation at $3000 \mathrm{rpm}$ at room temperature for $5 \mathrm{~min}$. The bottom organic phase was collected and concentrated under a stream of nitrogen at $55^{\circ} \mathrm{C}$ giving a residue that was resuspended in $600 \mu \mathrm{L}$ of hexane. Aliquots of this mixture were analyzed by using GC-MS with an Agilent 7890A-5975 C system equipped with Agilent HP-INNOWax $(30 \mathrm{~m} \times 250 \mu \mathrm{m} \times 0.25 \mu \mathrm{m})$. Helium (constant flow $1 \mathrm{~mL} / \mathrm{min}$ ) was used as the carrier gas. The temperature of the injector was $250^{\circ} \mathrm{C}$ and the following temperature program was applied: $100^{\circ} \mathrm{C}$

Table 2 Strains constructed and used in this study

\begin{tabular}{|c|c|c|}
\hline Strain & Genotype $^{a}$ & Reference \\
\hline $6803 y u$ & $\begin{array}{l}\text { Synechocystis sp. PCC6803 Wild-type, Glucose- } \\
\text { tolerance }\end{array}$ & Prof. Xu X. \\
\hline GQ3 & slr0168: :Omega $P_{\text {rbc }} s / r 1609$ & This study \\
\hline GQ8 & slr1609: :CCEII & This study \\
\hline$\overline{\text { GQ5 }}$ & $\begin{array}{l}\text { slr0168: :omega } P_{\text {rbc }} \text { far (jojoba), psbA2: :CK2 } \\
P_{\text {psbA2 } S / r 1609}\end{array}$ & This study \\
\hline GQ6 & slr0168:: omega $P_{\text {rbc }}$ far (jojoba); s/r1609::CK2 & This study \\
\hline $\begin{array}{l}\text { Syn- } \\
\text { XT14 }\end{array}$ & slr0168::Omega $P_{\text {rbc }}$ far (jojoba) $T_{\text {rbc }}$ & [4] \\
\hline
\end{tabular}

$\mathrm{kb}$ DNA fragment containing the promoter of $r b c$ operon. $T_{\mathrm{rbc}} 0.2 \mathrm{~kb}$ DNA

fragment downstream of $r b c S$ gene. $P_{\mathrm{psbA} 2}, 1.5 \mathrm{~kb}$ DNA fragment containing

the promoter of $p s b A 2$ gene. All promoters and terminators mentioned here are from Synechocystis sp. PCC 6803. for $1 \mathrm{~min}$, increase of $5^{\circ} \mathrm{C} \mathrm{min}^{-1}$ to $200^{\circ} \mathrm{C}$ then increase of $25^{\circ} \mathrm{C} \mathrm{min}{ }^{-1}$ to $240^{\circ} \mathrm{C}$ for $15 \mathrm{~min}$.

Previous work in our lab showed that fatty alcohol and alkane can not be detected in relative culture media (data not shown). For extraction of fatty alkanes, Synechocystis cells at stationary phase (about $240 \mathrm{~h}$ ) were harvested from $200 \mathrm{~mL}$ of culture by centrifugation. The cells were resuspended in $10 \mathrm{~mL}$ of TE buffer (pH8.0) and then lysed by sonication. The lysate added with $30 \mu \mathrm{g}$ of eciosane as internal standard was extracted for $1 \mathrm{~h}$ at room temperature with $10 \mathrm{~mL}$ of 2:1 (v/v) $\mathrm{CHCl}_{3}: \mathrm{CH}_{3} \mathrm{OH}$. The same following sample preparation and GC-MS analysis methods described above were used for fatty alkane analysis.

The same extraction methods described above for fatty alkane analysis were used for fatty alcohol, except adding $20 \mu \mathrm{g}$ of 1-pentadecanol as the internal standard. The following temperature program was applied here: $50^{\circ} \mathrm{C}$ for $1 \mathrm{~min}$, increase of $20^{\circ} \mathrm{C} \mathrm{min}{ }^{-1}$ to $180^{\circ} \mathrm{C}$ then increase of $10^{\circ} \mathrm{C} \mathrm{min}{ }^{-1}$ to $240^{\circ} \mathrm{C}$ for $20 \mathrm{~min}$.

\section{Additional material}

Additional file 1: Figure 1. Western blot analysis of overexpressed AAS protein in GQ3 and GQ5 mutant with anti-His-tag antibody. Table 1.

Primers used in this study.

\section{Abbreviations}

ACP: acyl carrier protein; AAR: acyl-ACP reductase; ADC: aldehyde decarbonylase; FAR: fatty acyl-COA reductase; ACS: acyl-CoA synthetase; AAS: acyl-ACP synthetase; ACC: acetyl-CoA carboxylase; FAS: fatty acid synthase; GPAT: glycerol-3-phosphate-acyl transferase; ACAT: acyl-CoA-ACP transferase; ACR: acyl-CoA reductase. 


\section{Acknowledgements}

This work was supported by grants from the National Basic Research Program of China (973: 2011CBA00907), National Science Foundation of China (30970048), Knowledge Innovation Program of the Chinese Academy of Sciences (KSCX2-EW-G-1-4), Shell Research Limited (Grant 51010653-09OS) and the "100-Talent Program of the Chinese Academy of Sciences" foundation (Grant O91001110A).

\section{Author details}

'Key Laboratory of Biofuels, Qingdao Institute of Bioenergy and Bioprocess Technology, Chinese Academy of Sciences, No. 189 Songling Road, Qingdao 266101, China. ${ }^{2}$ Graduate School of Chinese Academy of Sciences, Beijing 100049, China

\section{Authors' contributions}

XL conceived of the study. XL and QG designed the experiments. QG carried out the construction and cultivation of Synechocystis sp. PCC683 mutant strains. QG carried out extraction and analysis of free fatty acids, fatty alkanes and fatty alcohols. WW and HZ participated in GC-MS analysis. XL, QG and WW wrote the manuscript. All authors read and approved the final manuscript.

\section{Competing interests}

The authors declare that they have no competing interests.

Received: 18 November 2011 Accepted: 21 March 2012

Published: 21 March 2012

\section{References}

1. Yan Y, Liao JC: Engineering metabolic systems for production of advanced fuels. J Ind Microbiol Biotechnol 2009, 36:471-479.

2. Keasling JD, Chou H: Metabolic engineering delivers next-generation biofuels. Nat Biotechnol 2008, 26:298-299.

3. Lindberg P, Park S, Melis A: Engineering a platform for photosynthetic isoprene production in cyanobacteria, using Synechocystis as the model organism. Metab Eng 2010, 12:70-79.

4. Tan X, Yao L, Gao Q, Wang W, Qi F, et al: Photosynthesis driven conversion of carbon dioxide to fatty alcohols and hydrocarbons in cyanobacteria. Metab Eng 2011, 13:169-176.

5. Atsumi S, Higashide W, Liao JC: Direct photosynthetic recycling of carbon dioxide to isobutyraldehyde. Nat Biotechnol 2009, 27:1177-U1142.

6. Schirmer A, Rude MA, Li X, Popova E, del Cardayre SB: Microbial biosynthesis of alkanes. Science 2010, 329:559-562.

7. Metz JG, Pollard MR, Anderson L, Hayes TR, Lassner MW: Purification of a jojoba embryo fatty acyl-coenzyme $A$ reductase and expression of its cDNA in high erucic acid rapeseed. Plant Physiol 2000, 122:635-644.

8. Kaczmarzyk D, Fulda M: Fatty acid activation in cyanobacteria mediated by acyl-acyl carrier protein synthetase enables fatty acid recycling. Plant Physiol 2010, 152:1598-1610.

9. Williams JGK: Construction of specific mutations in photosystem-ii photosynthetic reaction center by genetic-engineering methods in Synechocystis-6803. Methods Enzymol 1988, 167:766-778.

10. Mann N, Carr NG: Control of macromolecular composition and cell division in the blue-green algae Anacystis nidulans. J Gen Microbiol 1974, 83:399-405.

11. Warui DM, Li N, Norgaard H, Krebs C, Bollinger JM, et al: Detection of formate, rather than carbon monoxide, as the stoichiometric coproduct in conversion of fatty aldehydes to alkanes by a cyanobacterial aldehyde decarbonylase. J Am Chem Soc 2011, 133:3316-3319.

12. Anderson MS, Raetz CR: Biosynthesis of lipid A precursors in Escherichia coli. A cytoplasmic acyltransferase that converts UDP-Nacetylglucosamine to UDP-3-O-(R-3-hydroxymyristoyl)-Nacetylglucosamine. J Biol Chem 1987, 262:5159-5169.

13. Rock CO, Jackowski S: Regulation of phospholipid synthesis in Escherichia coli. Composition of the acyl-acyl carrier protein pool in vivo. I Biol Chem 1982, 257:10759-10765.

14. Rumley MK, Therisod H, Weissborn AC, Kennedy EP: Mechanisms of regulation of the biosynthesis of membrane-derived oligosaccharides in Escherichia coli. J Biol Chem 1992, 267:11806-11810.
15. $X u X D$, Yin $C T$, Li WZ, Du Y, Kong RQ: Identification of a gene, $c c r-1$ (s/11242), required for chill-light tolerance and growth at $15^{\circ} \mathrm{C}$ in Synechocystis sp PCC 6803. Microbiol-Sgm 2007, 153:1261-1267.

16. Neilan BA, Roberts AA, Copp JN, Marahiel MA: The Synechocystis sp PCC6803 Sfp-type phosphopantetheinyl transferase does not possess characteristic broad-range activity. ChemBioChem 2009, 10:1869-1877.

17. Karakaya $\mathrm{H}$, Mann $\mathrm{NH}$ : Mutagenesis of the tal gene-encoding transaldolase in the Cyanobacterium, Anabaena sp PCC7120. Turk J Biol 2008, 32:135-141.

18. Porter RD: DNA transformation. Methods Enzymol 1988, 167:703-712.

19. Williams JGK: construction of specific mutations in photosystem-ii photosynthetic reaction center by genetic-engineering methods in Synechocystis-6803. Method Enzymol 1988, 167:766-778.

20. Bligh EG, Dyer WJ: A rapid method of total lipid extraction and purification. Can J Biochem Physiol 1959, 37:911-917.

doi:10.1186/1754-6834-5-17

Cite this article as: Gao et al:: Effects of fatty acid activation on photosynthetic production of fatty acid-based biofuels in Synechocystis sp. PCC6803. Biotechnology for Biofuels 2012 5:17.

\section{Submit your next manuscript to BioMed Central and take full advantage of:}

- Convenient online submission

- Thorough peer review

- No space constraints or color figure charges

- Immediate publication on acceptance

- Inclusion in PubMed, CAS, Scopus and Google Scholar

- Research which is freely available for redistribution

Submit your manuscript at www.biomedcentral.com/submit
Ciomed Central 